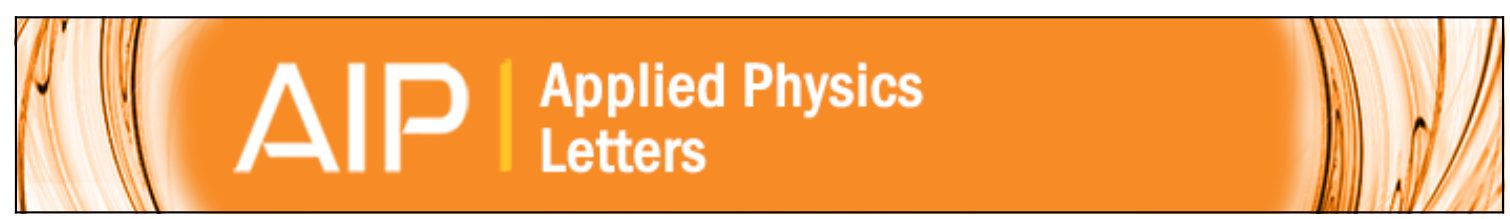

\title{
Separation of intrinsic and extrinsic optical absorption in a fluoride glass
}

John M. Jewell, Glen M. Williams, James Jaganathan, I. D. Aggarwal, and Paul Greason

Citation: Applied Physics Letters 59, 1 (1991); doi: 10.1063/1.105564

View online: http://dx.doi.org/10.1063/1.105564

View Table of Contents: http://scitation.aip.org/content/aip/journal/apl/59/1?ver=pdfcov

Published by the AIP Publishing

\section{Articles you may be interested in}

Intrinsic and extrinsic diffusion of indium in germanium

J. Appl. Phys. 106, 063534 (2009); 10.1063/1.3226860

High-resolution three-dimensional scanning optical image system for intrinsic and extrinsic contrast agents in tissue

Rev. Sci. Instrum. 73, 172 (2002); 10.1063/1.1424907

Intrinsic optical bistability in a semiconductor doped glass filter

Am. J. Phys. 63, 844 (1995); 10.1119/1.17810

Optical absorption and luminescence in lithium fluoride TLD100

J. Appl. Phys. 56, 2883 (1984); 10.1063/1.333826

Optical Absorption of Cobalt in Manganese Fluoride

J. Chem. Phys. 44, 2317 (1966); 10.1063/1.1727041

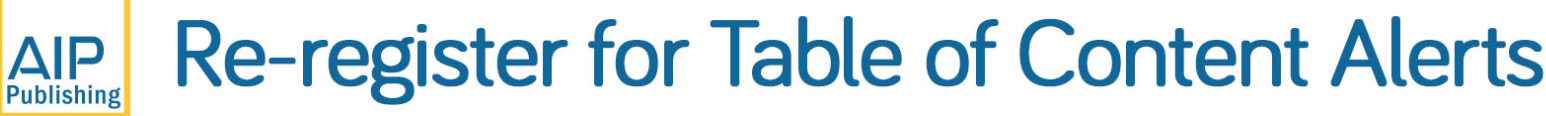




\section{Separation of intrinsic and extrinsic optical absorption in a fluoride glass}

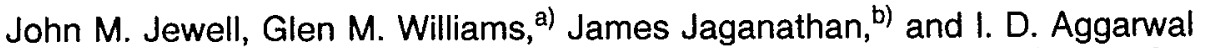

Optical Materials Research Group, Code 6505, Optical Sciences Division, Naval Research Laboratory, Washington, DC 20375-5000

Paul Greason

UDRI, University of Dayton, Dayton, Ohio 45469

(Received 21 December 1990; accepted for publication 2 April 1991)

The contribution of impurity ions to the total optical absorption of a heavy metal fluoride glass has been determined at 532 and $1064 \mathrm{~nm}$. Four $\mathrm{ZrF}_{4}-\mathrm{BaF}_{2}-\mathrm{LaF}_{3}-\mathrm{AlF}_{3}-\mathrm{NaF}$ glasses were prepared from various purity raw materials. The absorption coefficients of these glasses range from 0.92 to $45.4 \times 10^{-4} \mathrm{~cm}^{-1}$ at $1064 \mathrm{~nm}$ and from 7.43 to $11.1 \times 10^{-4}$ $\mathrm{cm}^{-1}$ at $532 \mathrm{~nm}$ as determined by laser calorimetry. The concentrations of $\mathrm{Fe}, \mathrm{Ni}, \mathrm{Cu}$, and $\mathrm{Co}$ ions in each glass were determined by graphite furnace atomic absorption spectroscopy.

These two measurements enable the absorption, due to transition metal ions to be differentiated from the intrinsic absorption of the glass. At $1064 \mathrm{~nm}$, the absorption coefficient of these glasses is controlled entirely by the transition metal ion content. However, at $532 \mathrm{~nm}$, the absorption by the transition metal ions accounts for $4-42 \%$ of the total absorption depending on impurity concentration. The intrinsic absorption of this fluoride glass calculated from these data at $532 \mathrm{~nm}$ is $(7.69 \pm 0.99) \times 10^{-4} \mathrm{~cm}^{-1}$.

Heavy metal fluoride (HMF) glasses are promising materials for optical applications in the near ultraviolet, visible, and infrared since they have a broad transmission window that extends from $200 \mathrm{~nm}$ to beyond $8 \mu \mathrm{m}$. In addition, these glasses have relatively low intrinsic scattering, small stress-optic coefficients, shallow dispersion curves, and very small intrinsic absorption. ${ }^{1-3}$

The total optical absorption coefficient of any material can be expressed in terms of intrinsic and extrinsic contributions:

$$
\beta_{\text {glass }}=\beta_{\text {int }}+\beta_{\text {ext }} \text {, }
$$

where $\beta_{\text {int }}$ the absorption that arises from the intrinsic electronic and vibrational absorptions of the glass, and $\beta_{\text {ext }}$ is the extrinsic absorption of the impurities in the system. In most cases, the optical absorption of HMF glasses is dominated by the absorption by impurities. This letter reports on a study of the effect of raw materials purity on the absorption coefficient of HMF glasses in the visible and infrared. Comparison of direct measurements of the transition metal content with the absorption coefficient at both 532 and $1064 \mathrm{~nm}$ enable the extrinsic absorption to be separated from intrinsic absorption.

Four samples of a $\mathrm{ZrF}_{4}-\mathrm{BaF}_{2}-\mathrm{LaF}_{3}-\mathrm{AlF}_{3}-\mathrm{NaF}(\mathrm{ZB}-$ LAN) were obtained from industrial sources. ${ }^{4-6}$ These samples were prepared from raw materials ranging in purity from typical reagent grade to ultrahigh purity. The samples were cut and polished into the disk or bar-shaped specimens required for laser calorimetry, and a small portion of each glass was retained for analysis of impurity content. The critical surfaces were finished to a scratch/dig of $20 / 10$ and a fatness of $\lambda / 40$.

\footnotetext{
'Also with Virginia Polytechnic Institute and State University, Blacksburg, VA 24061.

b)Also with Geo Centers Inc., Fort Washington, MD 20744.
}

The total transition metal ion content of each glass was determined using graphite furnace atomic absorption spectroscopy (GFAAS). The details of this analysis are given elsewhere. ${ }^{7,8}$ The total transition metal $\left(\mathrm{Fe}^{2+}, \mathrm{Co}^{2+}\right.$, $\mathrm{Ni}^{2+}$, and $\mathrm{Cu}^{2+}$ ) contents for the four ZBLAN glasses are given in Table $I$. The purity of the starting raw materials has a significant effect on the purity of the glass. For example, ZBLAN-1, which was made from low-purity materials, has 40 times more $\mathrm{Fe}$ and 35 times more $\mathrm{Cu}$ than ZBLAN-4, which was made with ultrapure materials. There is less of an effect of the materials purity on the $\mathrm{Ni}$ content, and all the materials used gave glasses with Co concentrations below the detectability limit.

Laser calorimeter measurements were performed on each sample using a Spectra Physics Model 3800 Nd:YAG laser source with a KTP frequency doubling crystal. For the $1064 \mathrm{~nm}$ experiment the laser was operated continuous wave $(\mathrm{cw})$. For the $532 \mathrm{~nm}$ experiment the laser was operated mode locked and $Q$-switched (with a duty cycle of 1 $\mathrm{kHz}$ ) to facilitate frequency doubling. A typical $Q$ switched pulse consisted of a 180-ns-long train of 100 ps pulses at a $82 \mathrm{MHz}$ repetition rate. If the nonlinearity in the optical absorption is assumed to be negligible, this complicated temporal output has the same effect on the sample as $\mathrm{cw}$ output. The average power for the measurements was $1 \mathrm{~W}$ and $300 \mathrm{~mW}$ at 1064 and $532 \mathrm{~nm}$, respectively. A complete description of the laser calorimetry experiment is given elsewhere. 9,10

Table II shows the total absorption coefficients, $\beta_{\text {glass, }}$ at 532 and $1064 \mathrm{~nm}$ for the four ZBLAN glasses. The laser calorimetry data follow the expected trend of decreasing absorption coefficient with decreasing transition metal content. However, the transition metal content appears to have a larger effect on the absorption at $1064 \mathrm{~nm}$ than at $532 \mathrm{~nm}$. The absorption coefficient of ZBLAN-1 at 1064 $\mathrm{nm}$ is nearly 50 times larger than that of ZBLAN-4. However at $532 \mathrm{~nm}$ the absorption coefficient of ZBLAN-1 is 
TABLE I. Results of GFAAS analysis for transition metals concentrations in ppb. The sign indicates that the value was below the detectability limit of the GFAAS measurement.

\begin{tabular}{lrrrr}
\hline \hline Glass ID & Fe & Co & Ni & \multicolumn{1}{c}{ Cu } \\
\hline ZBLAN-1 & 14866 & $<7$ & 122 & 1760 \\
ZBLAN-2 & 1361 & $<7$ & 214 & 55 \\
ZBLAN-3 & 733 & $<7$ & $<19$ & 134 \\
ZBLAN-4 & 379 & $<7$ & 63 & 55 \\
\hline \hline
\end{tabular}

only 1.5 times larger than that of ZBLAN-4.

The intrinsic absorption, $\beta_{\text {int }}$, at these wavelengths arises primarily from the Urbach tail and is given by

$$
\beta_{\text {int }}=A \exp (-\alpha / T),
$$

where $A$ and $\alpha$ are constants. ${ }^{11}$ In fact, at $1 \mu \mathrm{m}$, the contribution from the multiphonon edge is less than $10^{-25}$ $\mathrm{cm}^{-1}{ }^{1}$ The extrinsic absorption, $\beta_{\text {ext }}$, arises from impurity ion absorption and is given by

$$
\beta_{\mathrm{ext}}=\sum_{n} C_{n} \beta_{\mathrm{ion}, n}
$$

where $C_{n}$ and $\beta_{\text {ion, } n}$ are the concentration and absorption coefficient of ion " $n$ ", respectively.

The GFAAS data from Table I were used to calculate the extrinsic absorption, $\beta_{\text {ext }}$, that arises from the transition metal ions in each glass. The absorption coefficients for the transition metals, $\beta_{\text {ion }}$, were taken from the literature. ${ }^{12}$ Figure 1 shows the measured absorption coefficients, $\beta_{\text {glass }}$ at $1064 \mathrm{~nm}$ for the four ZBLAN glasses as a function of the calculated extrinsic absorption coefficient, $\beta_{\text {ext }}$. The fact that the measured values fall very close to the $45^{\circ}$ line which defines $\beta_{\text {glass }}=\beta_{\text {ext }}$ indicates that $\beta_{\text {int }}<\beta_{\text {ext }}$, i.e., the absorption of $1064 \mathrm{~nm}$ light by ZBLAN glass is controlled entirely by the concentration of $\mathrm{Fe}, \mathrm{Co}, \mathrm{Ni}$, and $\mathrm{Cu}$. Regression analysis indicates that the values of $\beta_{\text {glass }}$ actually fall on a line that is parallel to the line defined by $\beta_{\text {glass }}=\beta_{\text {ext }}$.

Table III gives the calculated extrinsic absorption, $\beta_{\mathrm{ext}}$, at $532 \mathrm{~nm}$ that arises from the transition metal content at $532 \mathrm{~nm}$. The values of $\beta_{\text {int }}$, calculated using Eq. (1), are also given in Table III. This calculation assumes that there is no significant contribution from other ions to $\beta_{\text {ext }}$ at 532 $\mathrm{nm}$. Unlike the absorption at $1064 \mathrm{~nm}, \beta 1$ at $532 \mathrm{~nm}$ is not determined entirely by the transition metal content. In fact, the contribution of $\beta_{\text {ext }}$ to $\beta_{\text {glass }}$ ranges from $42.5 \%$ for ZBLAN-1 to $4.5 \%$ for ZBLAN-4. The average value of the intrinsic absorption at $532 \mathrm{~nm}$ is $(7.69 \pm 0.99) \times 10^{-4}$

TABLE II. Absorption coefficients, $\beta_{\text {glass, }}$ for ZBLAN glasses.

\begin{tabular}{lcc}
\hline \hline Glass ID & $\begin{array}{c}\beta_{\text {glass }} @ 532 \mathrm{~mm} \\
\left(\times 10^{-4} \mathrm{~cm}^{-1}\right)\end{array}$ & $\begin{array}{c}\beta_{\text {glass }} @ 1064 \mathrm{~nm} \\
\left(\times 10^{-4} \mathrm{~cm}^{-1}\right)\end{array}$ \\
\hline ZBLAN-1 & $11.1 \pm 0.37$ & $44.0 \pm 0.25$ \\
ZBLAN-2 & $9.32 \pm 0.46$ & $3.72 \pm 0.16$ \\
ZBLAN-3 & $9.14 \pm 0.25$ & $1.53 \pm 0.06$ \\
ZBLAN-4 & $7.43 \pm 0.19$ & $0.92 \pm 0.02$ \\
\hline
\end{tabular}

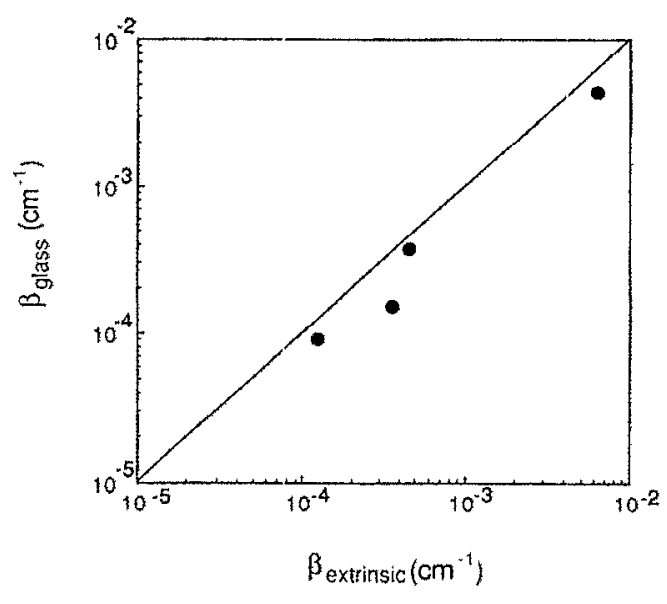

FIG. 1. Measured absorption coefficient $\beta_{\text {glass }}$ of ZBLAN glasses at 1064 $\mathrm{nm}$ as a function of the calculated extrinsic absorption, $\beta_{\mathrm{ext}}$.

$\mathrm{cm}^{-1}$. This value agrees well with the value taken from the extrapolation of $U V$ edge data for a $\mathrm{ZrF}_{4}-\mathrm{BaF}_{2}-\mathrm{LaF}_{3}$ glass, $2 \times 10^{-3} \mathrm{~cm}^{-1} 13$

In general, the laser calorimetry data are in good agreement with the data from the GFAAS analysis of the transition metal. The scatter in the values of $\beta_{\text {int }}$ at $532 \mathrm{~nm}$ and the fact that measured values of $\beta_{\text {glass }}$ at $1064 \mathrm{~nm}$ fall below the $\beta_{\text {glass }}=\beta_{\text {ext }}$ may result from a number of different factors including: (1) variation in oxidation state of the transition metals, (2) over estimation of the concentration of ions present at levels less than the detectability limit of GFAAS, (3) absorption by other ions, (4) errors in the values of $\beta_{\text {int }}$ and (5) possible fluorescence of transition metals.

First, it is possible that the oxidation states of the transition metals are not all the same. The calculation of $\beta_{\text {ext }}$ assumed that all of the transition metals are present in the $2+$ oxidation state. Reduction of iron to the $\mathrm{Fe}^{3+}$ state, oxidation of copper to the $\mathrm{Cu}^{1+}$ state, or the reduction of cobalt and nickel to the metallic state would reduce the absorption coefficient by an amount proportional to the concentration of these alternate oxidation states. France et $a l .{ }^{14}$ studied the effect of melting atmosphere on the oxidation state of transition metals at the 400-1000 ppm level in a ZBLAN glass containing $\mathrm{PbF}_{2}$. Their work indicates that while iron remains almost entirely in the $\mathrm{Fe}^{2+}$ state, copper is reduced to the $\mathrm{Cu}^{1+}$ state unless the glass is melted under $\mathrm{O}_{2}$ atmosphere. Additionally, they found no reduction of cobalt and nickel under normal melting conditions. Although some variation in the oxidation state is possible, differences in the oxidation state probably do not

TABLE III. Calculated extrinsic absorption, $\hat{E}_{\text {ext }}$, and intrinsic absorption, $\beta_{\text {nnt }}$ for ZBLAN glasses at $532 \mathrm{~nm}$.

\begin{tabular}{lcc}
\hline \hline Glass ID & $\beta_{\text {ext }}\left(\times 10^{-4} \mathrm{~cm}^{-1}\right)$ & $\beta_{\text {int }}\left(\times 10^{-4} \mathrm{~cm}^{-1}\right)$ \\
\hline ZBLAN-1 & 4.72 & 6.38 \\
ZBLAN-2 & 0.76 & 8.55 \\
ZBLAN-3 & 0.39 & 8.74 \\
ZBLAN-4 & 0.33 & 7.10 \\
\hline \hline
\end{tabular}


contribute significantly to the discrepancies mentioned above. However, these changes in oxidation would shift the value of $\beta_{\text {glass }}$ toward the line which defines $\beta_{\text {glass }}=\beta_{\text {ext }}$.

Second, the cobalt concentration of each glass was below the detectability limit of GFAAS, and the nickel concentration of ZBLAN-3 was also below the detectability limit. Because all of the $\beta_{\text {ext }}$ were calculated assuming that these transition metals were present at levels equal to the detectability limit, the calculation gives an upper limit for the calculation of $\beta_{\text {ext }}$ at $1064 \mathrm{~nm}$. Therefore this factor cannot explain why $\beta_{\text {glass }}<\beta_{\text {ext }}$ at $1064 \mathrm{~nm}$. However, the inability to determine the concentration of cobalt to less than $7 \mathrm{ppb}$ could be a significant contributing factor to the scatter in the value $\beta_{\text {int }}$ at $532 \mathrm{~nm}$. For example, $7 \mathrm{ppb}$ of $\mathrm{Co}^{2}+$ contributes $4 \%$ of the $\beta_{\text {ext }}$ for ZBLAN-1, $21 \%$ of the $\beta_{\text {ext }}$ for ZBLAN-2, $40 \%$ of the $\beta_{\text {ext }}$ for ZBLAN-3, and $48 \%$ of the $\beta_{\text {ext }}$ for ZBLAN-4.

The possibility of absorption by ions other than $\mathrm{Fe}, \mathrm{Co}$, $\mathrm{Ni}$, and $\mathrm{Cu}$ must also be considered. There are a number of ions, including $\mathrm{Ti}^{3+}, \mathrm{V}^{3+}, \mathrm{Cr}^{3+}, \mathrm{Nd}^{3+}, \mathrm{Er}^{3+}$, and $\mathrm{Pr}^{3+}$, that give rise to absorptions at 532 and/or $1064 \mathrm{~nm}^{12,13}$ If significant concentrations of $\mathrm{V}^{3+}, \mathrm{Pr}^{3+}$, and $\mathrm{Er}^{3+}$ were present, the $\beta_{\text {glass }}$ at $1064 \mathrm{~nm}$ would be greater than the calculated value of $\beta_{\text {ext }}$. However, $\mathrm{Nd}^{3+}, \mathrm{Ti}^{3+}$, and $\mathrm{Cr}^{3+}$ have no absorptions at $1064 \mathrm{~nm}$, and therefore may be present at concentrations which could contribute to the scatter in $\beta_{\text {int }}$ at $532 \mathrm{~nm}$.

The values used for $\beta_{\text {ion }}$ are also a critical factor for the calculation of $\beta_{\text {ion }}$ at $532 \mathrm{~nm}$ and $\beta_{\text {ext }}$ at $1064 \mathrm{~nm}$. The values used here were determined for the transition metal in $\mathrm{GdF}_{3}$ containing $\mathrm{ZrF}_{4}$-based glasses. ${ }^{12}$ Although the composition of the ZBLAN glass in this study is different, the work of France et al. ${ }^{14}$ indicates that the coordination of the $\mathrm{Fe}, \mathrm{Co}, \mathrm{Ni}$, and $\mathrm{Co}$ ions will not be changed significantly. However, it is very plausible that differences in density and molar volume could alter the ligand field strength and therefore shift the position of the absorption bands. A shift in the absorption band would change the $\beta_{\text {ion }}$ at both 532 and $1064 \mathrm{~nm}$. Analogous effects have been observed in oxide glasses. ${ }^{15,16}$

The final factor to consider is fluorescence. Fluorescence has been observed in HMF glasses for a number of ions including $\mathrm{Fe}, \mathrm{Co}, \mathrm{Ni}$, and $\mathrm{Cu},{ }^{1,17,18}$ and must be considered as a possible source of error in the calculation of $\beta_{\text {ext }}$. If some fraction of the power is absorbed by the transition metal ions and then released as photons, the measured $\beta_{\text {glass }}$ will be reduced by a factor proportional to the quantum efficiency of this radiative decay for the transition metal ions.

'M. G. Drexhage, Treatise on Materials Science and Technology (Academic, New York, 1985) Vol 26, pp. 151-243.

${ }^{2}$ D. C. Tran, G. H. Sigel Jr., and B. Bendow, J. Lightwave Technol. LT-2, 566 (1984).

${ }^{3}$ P. W. France, S. F Carter, M. W. Moore, and C. R. Day, Br. Telecom. Tech. J. 5, 12, (1987).

${ }^{4}$ Owens-Corning Figerglas Corp., Granville, OH 43023.

${ }^{5}$ Galileo Electro Optics Inc, Sturbridge, MA 01566.

${ }^{6}$ Infrared Fiber Systems, Silver Spring, MD 20904.

${ }^{7}$ J. Jaganathan, K. J. Ewing, and I. D. Aggarwal, Micro. Chem. J. 41, 106 (1990).

${ }^{8}$ J. Jaganathan, K. J. Ewing, and I. D. Aggarwal, Spectrochemica Acta. (to be published).

${ }^{9}$ M. Hass, J. W. Davisson, H. B. Rosenstock, and J. Babiskin, Appl. Opt. 14, 1128 (1975).

${ }^{10}$ H. B. Rosenstock, J. Appl. Phys. 50, 102 (1979).

${ }^{11}$ J. D. Dow and D. Redfield, Phys. Rev. B 5, 594 (1972).

${ }^{12}$ Y. Ohishi, S. Mitachi, T. Kanamori, and T. Manabe, Phys. Chem. Glasses 24, 135 (1983).

${ }^{13}$ R. N. Brown, B. Bendow, M. G. Drexhage, and C. T. Moynihan, Appl. Opt. 21, 361 (1982).

${ }^{14}$ P. W. France, S. F. Carter, and J. M. Parker, Phys. Chem. Glasses 27, 32 (1986).

${ }^{15}$ C. R. Bamford, Phys. Chem. Glasses 3, 189 (1962).

${ }^{16} \mathrm{G}$. H. Sigel Jr., Treatise on Materials Science and Technology (Academic, New York, 1981), Vol. 22, pp. 5-89.

${ }^{17}$ O. Corre, M. Poulain, J. Lucas, and H. Bougault, Verres Refract. 34, 764 (1980).

${ }^{18}$ D. B. Hollis, S. Parke, and E. A. Harris, Mater. Sci. Forum 6, 621 (1985). 